\title{
Safety and effects of volume loading during transesophageal echocardiography in the pre-procedural work-up for left atrial appendage closure
}

Afonso B. Freitas-Ferraz, Mathieu Bernier*, Kim O'Connor, Jonathan Beaudoin, Jean Champagne, Jean-Michel Paradis, Gilles O'Hara, Guillem Muntané- Carol, Alberto Alperi, Laurent Faroux, Lucia Junquera and Josep Rodés-Cabau*

\begin{abstract}
Background: In patients undergoing left atrial appendage (LAA) closure, an accurate sizing of the LAA is key to optimize device sizing, procedural success and reduce complications. Previous studies have shown that intraprocedural volume loading increases LAA dimensions and improves device sizing. However, the safety and effects on LAA and device sizing of administering a fluid bolus during pre-procedural transesophageal echocardiography (TEE) are unknown. The aim of this study was to determine the safety and impact on LAA dimensions and device sizing of an intravenous (IV) fluid bolus administered during TEE in the setting of the pre-procedural work-up for LAA closure.

Methods: The study included a total of 72 patients who underwent TEE to assess suitability for LAAC and received a $500 \mathrm{ml}$ IV bolus of normal saline. The LAA landing zone (LZ) and depth were measured by TEE before and after volume loading, and these measurements were used to predict the device size implanted during a subsequent percutaneous LAAC procedure.

Results: There were no complications associated with volume loading. The baseline mean LZ was $19.6 \pm 3.6 \mathrm{~mm}$ at $90^{\circ}$, and $20.2 \pm 4.1 \mathrm{~mm}$ at $135^{\circ}$. Following fluid bolus, the maximum diameter increased $1.5 \pm 1.0 \mathrm{~mm}$ at $90^{\circ}(p<0.001)$, and $1.3 \pm 1.0 \mathrm{~mm}$ at $135^{\circ}(p<0.001)$. The baseline mean depth of the LAA was $26.5 \pm 5.5 \mathrm{~mm}$ at $90^{\circ}$, and $23.9 \pm 5.8 \mathrm{~mm}$ at $135^{\circ}$. After fluid bolus, the mean depth increased by $1.5 \pm 1.8 \mathrm{~mm}(p<0.001)$ and $1.6 \pm 2.0(p<0.001)$, at $90^{\circ}$ and $135^{\circ}$, respectively. Sizing based on post-bolus measurements of the $L Z$ significantly improved the agreement with the final device size selection during the procedure in $71.0 \%$ of cases (vs. $42.0 \%$ with pre-bolus measurements).
\end{abstract}

Conclusions: Volume loading during ambulatory TEE as part of the pre-procedural work-up of LAAC is safe and significantly increases LAA dimensions. This strategy may become the new standard, particularly in centers performing LAAC with no TEE guidance, as it improves LAA sizing and more accurately predicts the final device size.

Keywords: Left atrial appendage, Left atrial appendage closure, Watchman, Amplatzer, Ultraseal, Transesophageal echocardiography, Volume loading

\footnotetext{
* Correspondence: Mathieu.bernier@criucpq.ulaval.ca;

josep.rodes@criucpq.ulaval.ca

Department of Cardiology, Quebec Heart \& Lung Institute, Laval University,

2725, chemin Sainte-Foy, Quebec City G1V 4G5, Quebec, Canada
}

C The Author(s). 2021 Open Access This article is licensed under a Creative Commons Attribution 4.0 International License, which permits use, sharing, adaptation, distribution and reproduction in any medium or format, as long as you give appropriate credit to the original author(s) and the source, provide a link to the Creative Commons licence, and indicate if changes were made. The images or other third party material in this article are included in the article's Creative Commons licence, unless indicated otherwise in a credit line to the material. If material is not included in the article's Creative Commons licence and your intended use is not permitted by statutory regulation or exceeds the permitted use, you will need to obtain permission directly from the copyright holder. To view a copy of this licence, visit http://creativecommons.org/licenses/by/4.0/. The Creative Commons Public Domain Dedication waiver (http://creativecommons.org/publicdomain/zero/1.0/) applies to the data made available in this article, unless otherwise stated in a credit line to the data. 


\section{Background}

Atrial fibrillation (AF) is the most common sustained cardiac rhythm disorder encountered in clinical practice and poses a major public health concern with high morbidity [1]. The most debilitating complication of AF is stroke, which is more severe, more likely to recur and is associated with a higher mortality than non-AF related strokes [2,3]. Oral anticoagulant effectively reduces the risk of ischemic stroke and systemic thromboembolism, and is considered the preferred therapy for most patients with AF $[4,5]$. Nevertheless, in those deemed poor candidates for long-term anticoagulation, percutaneous left atrial appendage closure (LAAC) provides a valid therapeutic alternative [4-6].

Currently, LAA sizing relies mainly on transesophageal echocardiography (TEE) measurements that are performed under fasting conditions, which may lead to a decrease in intravascular volume. Since the LAA is a compliant structure that responds to volume loading, sizing the LAA in these conditions may underestimate its true dimensions. Indeed, previous data have shown that administering 500-1000 $\mathrm{mL}$ of normal saline during the procedure is associated with an average increase of $10 \%$ in the width and depth of the LAA $[7,8]$. However, in the aforementioned studies, volume loading was performed intraprocedurally, in patients under general anesthesia and invasive hemodynamic monitoring. Moreover, some centers perform LAAC under fluoroscopic guidance only, and there has been a growing trend towards the use of intracardiac echocardiography as a potential alternative to TEE that mitigates the need for general anesthesia and expedite procedural logistics [9-11]. In these scenarios, an accurate preprocedural LAA sizing using TEE becomes even more important to optimize results and reduce complications related with inaccurate device sizing.

The aim of the present study was to determine the safety and impact on LAA dimensions and device sizing of an intravenous (IV) fluid bolus administered in the ambulatory setting, during the pre-procedural work-up for patient suitability for LAAC.

\section{Methods}

From January 2017 to February 2020, a total of 72 patients with AF who underwent an ambulatory TEE as part of the pre-procedural work-up for LAAC received an IV bolus of normal saline to ensure adequate volume loading. Indications for LAAC and the choice of the occluder device to be implanted in a subsequent scheduled intervention were based on the assessment of a multidisciplinary team, including interventional cardiologists, electrophysiologists and echocardiographists. All patients provided informed consent for the procedures and Ethics committee approval was obtained for data collection and analysis.

\section{Echocardiographic study}

All baseline TEE examinations were performed under conscious sedation, with midazolam alone or in combination with fentanyl, by an experienced cardiologist. Heart and respiratory rate, oxygen saturation and noninvasive blood pressure were monitored at baseline, and every 5 minutes throughout the duration of the procedure.

A multiplane TEE probe (Philips iE33 (X7-2t) or GE Vivid E9 (6VT-D)) was used to assess LAA morphology, landing zone (LZ) dimensions and the maximum depth of the dominant lobe, before and after the administration of $500 \mathrm{~mL}$ IV bolus of normal saline. For purposes of consistency and simplification, the LZ and depth were measured at $90^{\circ}$ and $135^{\circ}$, since these angles usually yield the largest dimensions [7]. The saline infusion was administered during or immediately after TEE probe insertion, and did not significantly increase procedural time since it takes place while standard steps are being performed. As per hospital protocol, during the time it takes for the bolus to be administered, we performed an evaluation of the heart valves and left ventricular function, leaving the detailed assessment of the LAA for last.

Images were digitally stored and retrospectively analyzed according to the device type that was finally implanted:

- - For the Watchman device (Boston Scientific, Natick, Massachusetts), the LZ was measured from the circumflex artery to a superior point $15 \mathrm{~mm}$ within the pulmonary vein ridge (PVR); and the LAA depth was measured from the landing zone to the most distal tip of the main lobe (Fig. 1a and b);

- - For the Amplatzer Cardiac Plug (AGA Medical Corporation, Golden Valley, MN) and the Ultraseal devices (Cardia, Eagan, Minnesota), the LAA orifice was measured from the PVR to the junction of the left atrium with the LAA at the level of the circumflex artery. The LZ was then measured at $10 \mathrm{~mm}$ within the LAA orifice and parallel to the line that defined the LAA orifice. Lastly, the depth was measured from a line that runs perpendicularly from the orifice to the posterior wall of the LAA (Fig. 1c and d).

All percutaneous LAA closure procedures were performed in a subsequent intervention (1-3 weeks later) under general anesthesia and TEE guidance. During LAA closure, intraprocedural volume loading was 

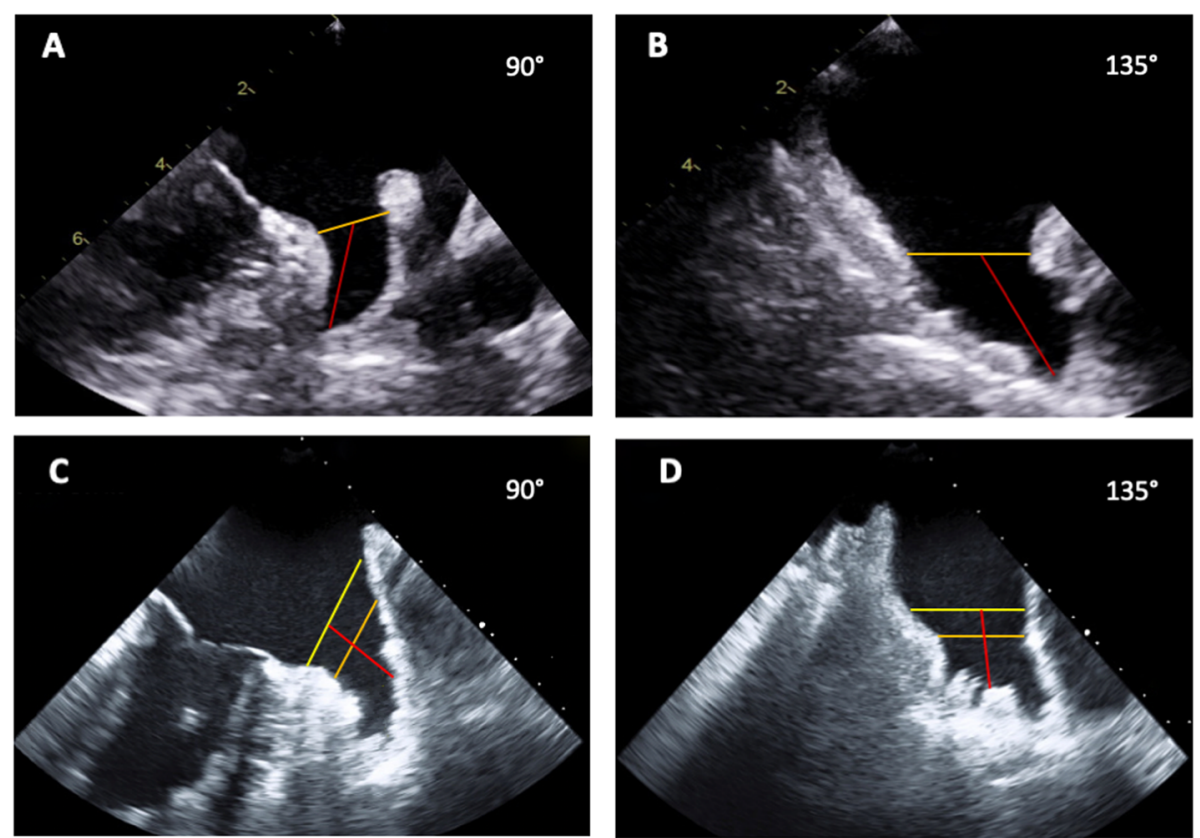

Fig. 1 Transesophageal echocardiography measurements for left atrial appendage closure using the Watchman device and the the Amplatzer Cardiac Plug/Ultraseal devices. For the Watchman device $(\mathbf{a} / \mathbf{b})$, the $L Z$ (orange line) measurement is taken from the circumflex artery medially to $1-2 \mathrm{~cm}$ laterally inside the limbus, and the depth (red line) is measured from the $L Z$ to the most distal tip of the main lobe. For the Amplatzer or the Ultraseal devices (c/d), the orifice (yellow line) is the line that connects the circumflex artery to the pulmonary vein ridge, and the LZ (orange line) is measured at 10-12 mm within the LAA orifice. The depth (red line) is measured from the orifice to the back wall of the LAA in a perpendicular line. LAA: left atrial appendage; LZ: landing zone

adapted to each patient volume status. The LA pressure was checked after transseptal puncture, and fluids were given to ensure a LA pressure $>10-12 \mathrm{mmHg}$. LAA measurements were performed before contrast administration.

The predicted device size based on the widest diameter of the LZ (as per the manufacturer' recommendations), before and after volume loading, was compared to the device that was actually implanted.

\section{Statistical analysis}

Categorical variables were expressed as a number (percentage) and continuous variables as mean (standard deviation) or median (interquartile range [IQR]: 25-75th percentile), according to their distribution. Assessment of normality for continuous data was performed using the Shapiro-Wilks test. Quantitative variables were analyzed with a paired Student t-test. All tests were 2-sided, and $p$ values $<0.05$ were considered significant. A simple regression model was used to investigate the influences of age, sex and body surface area on post volume loading LAA dimensions (delta). The analyses were performed using STATA (version 14.2; StataCorp LLC, College Station, Tx, USA). The data underlying this article will be shared on reasonable request to the corresponding author.

\section{Results}

Baseline clinical demographics of the study population are summarized in Table 1. The mean age of the patients was $75 \pm 8$ years, $29 \%$ were women and $15 \%$ had reduced left ventricular ejection fraction $(\mathrm{LVEF}<40 \%)$. The average $\mathrm{CHA}_{2} \mathrm{DS}_{2}$-VASc and HASBLED score was $4.3 \pm 1.6$ and $3.7 \pm 0.9$, respectively. In two patients $(2.8 \%)$ a pediatric TEE probe was used: one due to resistance encountered during probe insertion/advancement, and the other due to prior esophageal disease. All TEE procedures were performed without any complications and the administration of $500 \mathrm{~mL}$ IV bolus of normal saline was well tolerated by all patients.

The maximum diameter of the $\mathrm{LZ}$ and depth, before and after volume loading, are detailed in Table 2, and a visual representation of the changes in the LAA LZ and depth are depicted in Fig. 2. The baseline mean LZ was $19.6 \pm 3.6 \mathrm{~mm}$ at $90^{\circ}$, and $20.2 \pm 4.1 \mathrm{~mm}$ at $135^{\circ}$. After volume loading, the maximum diameter measured at the $\mathrm{LZ}$ increased to $21.1 \pm 3.6 \mathrm{~mm}$ at $90^{\circ}(p<0.001)$, and to $21.5 \pm 4.3 \mathrm{~mm}$ at $135^{\circ}(p<0.001)$, which corresponded to an overall average increase of $7.0 \%$. The baseline mean depth of the LAA was $26.5 \pm 5.5 \mathrm{~mm}$ at $90^{\circ}$, and $23.9 \pm$ $5.8 \mathrm{~mm}$ at $135^{\circ}$. Following volume loading, the mean depth increased to $28.0 \pm 5.5 \mathrm{~mm}(p<0.001)$ and $25.5 \pm$ 
Table 1 Baseline clinical demographics of the study population

\begin{tabular}{|c|c|}
\hline & $\begin{array}{l}\text { Study Population } \\
(n=72)\end{array}$ \\
\hline Age (years) & $75.2 \pm 7.7$ \\
\hline Female & $21(29.2)$ \\
\hline $\mathrm{BMI}\left(\mathrm{kg} / \mathrm{m}^{2}\right)$ & $29.4 \pm 8.7$ \\
\hline Diabetes mellitus & $27(37.5)$ \\
\hline Hypertension & $62(86.1)$ \\
\hline Peripheral artery disease & $9(12.5)$ \\
\hline Coronary artery disease & $32(44.4)$ \\
\hline Prior myocardial infarction & $8(11.1)$ \\
\hline Prior $C A B G$ & $13(18.1)$ \\
\hline Heart failure history & $13(18.1)$ \\
\hline Prior stroke/TIA & $26(36.1)$ \\
\hline \multicolumn{2}{|l|}{ Atrial fibrillation } \\
\hline Persistent/Permanent & $38(52.8)$ \\
\hline Paroxysmal & $34(47.2)$ \\
\hline $\mathrm{CHA}_{2} \mathrm{DS}_{2}$ VASc score & $4.3 \pm 1.6$ \\
\hline HASBLED score & $3.7 \pm 0.9$ \\
\hline LVEF (\%) & $59.5[50-60]$ \\
\hline Reduced LVEF $(<40 \%)$ & $11(15.3)$ \\
\hline Intraprocedural contrast administration (ml) & $82.0[59-113]$ \\
\hline
\end{tabular}

Values are mean $\pm S D, n(\%)$, or median [interquartile range]. $B M I$ body mass index, CABG coronary artery by-pass graft, $L V E F$ left ventricular ejection fraction, TIA transient ischemic attack

$6.3(p<0.001)$ at $90^{\circ}$ and $135^{\circ}$, respectively. Age, patient sex and body surface area did not have a significant impact on post bolus LAA dimensions.

Successful LAAC was achieved in all but 3 patients (3/ 72): two due to insufficient depth and the other due to an orifice that was too small for closure. There were no cases of device embolization. All procedures were performed under general anesthesia using the Watchman $(88.4 \%)$ or the ACP/Utraseal devices (11.6\%). The percentage of agreement between the device size that was actually implanted and the predicted size based on the largest LZ measured pre-procedurally are shown in Fig. 3. Sizing based on pre-bolus measurements predicted the final device chosen by the operator only in $42.0 \%$ of cases, and would have resulted in device oversizing in $13.0 \%$ and undersizing in $45 \%$. Sizing based on post-bolus measurements of the LZ significantly improved the agreement with the operator's device choice (71.0\%), and would have potentially resulted in oversizing in $21.7 \%$ and undersizing in $7.3 \%$.

\section{Discussion}

The results of the present study showed that the administration of an IV bolus of $500 \mathrm{~mL}$ of normal saline in the ambulatory setting is safe and results in significantly larger LAA dimensions. Sizing based on post volume loading measurements taken pre-procedurally significantly improved the agreement between the predicted device size determined by the manufacturers' recommendations and the final size of the device implanted.

LAA closure has emerged as a mechanical alternative to pharmacological stroke prevention in patients who cannot tolerate oral anticoagulation $[4,5,12]$. However, in order to optimize procedural success and reduce periprocedural complications that may offset the efficacy of the procedure, appropriate sizing of the occluder device is of paramount importance. Undersizing may result in device migration or inadequate sealing of the LAA cavity, which in turn could lead to peridevice leaks, thrombus formation and embolic stroke. On the other hand, excessive oversizing may lead to physical expulsion of the device from the LAA and may cause pericardial effusion/ tamponade due to perforation [13, 14]. Baseline preprocedural TEE to screen candidates for LAA closure is performed under fasting conditions, which may reduce intravascular volume and lead to inadvertent undersizing of the LAA. We observed an average increase of approximately $1.5 \mathrm{~mm}$ in the LZ and depth after volume loading, confirming the notion that the LAA is a compliant structure dependent on volume status. Previous studies have shown a similar, albeit slightly higher, increase of $\sim 2 \mathrm{~mm}$ in the width and depth of the LAA after volume loading $[7,8]$, which is clinically relevant since it likely results in upsizing the occluder device by an entire size. The likely reason for the more modest increase in size found in the herein cohort is the fact that the aforementioned studies administered on average a higher fluid bolus $(200-1000 \mathrm{ml})$, and relied on invasive left atrial pressure monitoring to ensure adequate volume status. In the ambulatory setting, since invasive hemodynamic monitoring is not

Table 2 Maximum diameter of the landing zone and depth of the left atrial appendage, before and after administration of $500 \mathrm{~mL}$ IV bolus of normal saline

\begin{tabular}{lllll}
\hline & Pre $\mathbf{5 0 0} \mathbf{~ m l}$ bolus & Post $\mathbf{5 0 0} \mathbf{~ m l}$ bolus & Delta (volume bolus - baseline) & $\boldsymbol{p}$ value \\
\hline $90^{\circ}$, landing zone $(\mathrm{mm})$ & $19.6 \pm 3.6$ & $21.1 \pm 3.6$ & $1.5 \pm 1.0$ & $<0.001$ \\
$90^{\circ}$, depth $(\mathrm{mm})$ & $26.5 \pm 5.5$ & $28.0 \pm 5.5$ & $1.5 \pm 1.8$ & $<0.001$ \\
$135^{\circ}$, landing zone $(\mathrm{mm})$ & $20.2 \pm 4.1$ & $21.5 \pm 4.3$ & $1.3 \pm 1.0$ & $<0.001$ \\
$135^{\circ}$, depth $(\mathrm{mm})$ & $23.9 \pm 5.8$ & $25.5 \pm 6.3$ & $1.6 \pm 2.0$ & $<0.001$ \\
\hline
\end{tabular}



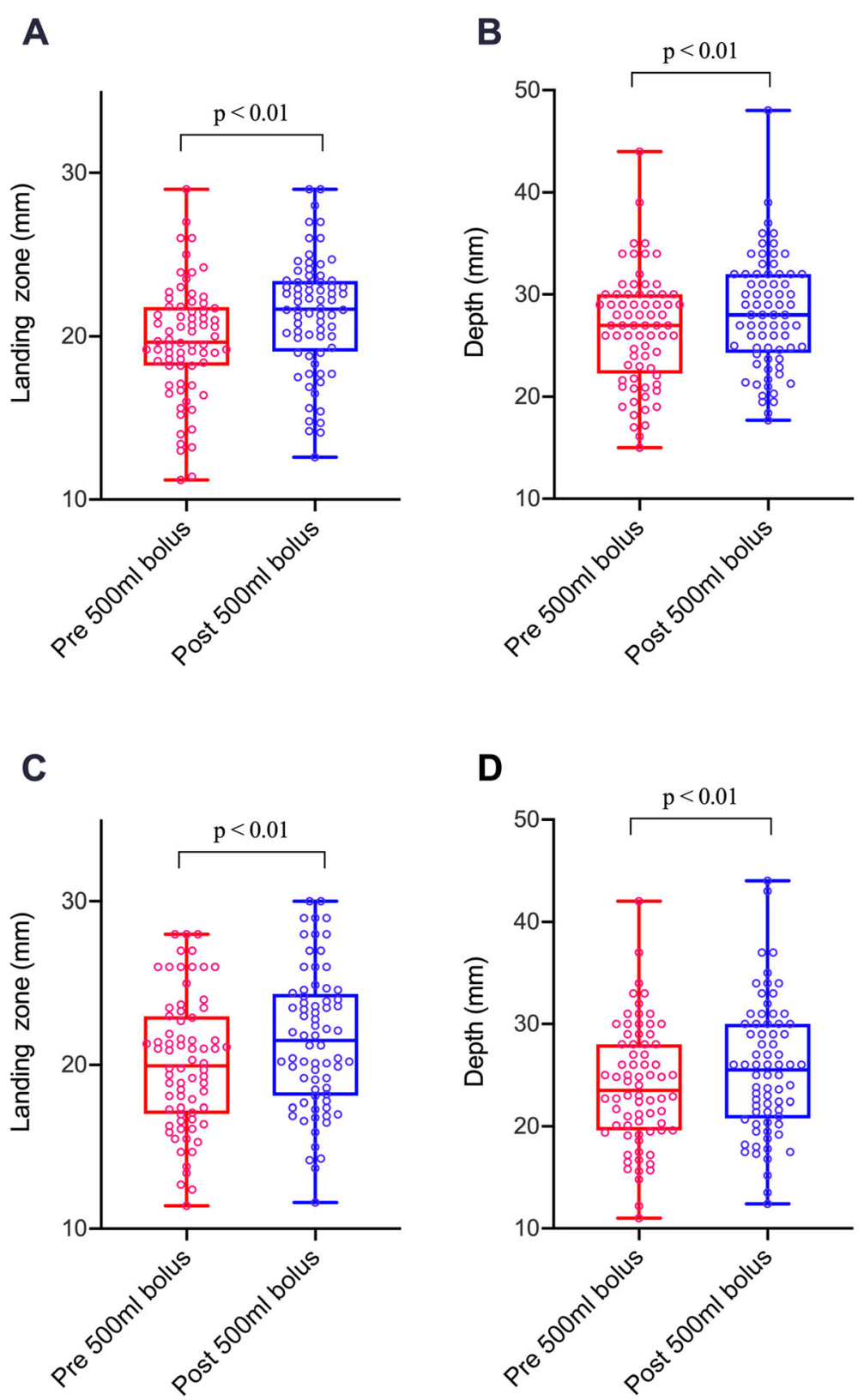

Fig. 2 Graphical representation showing the changes in the left atrial appendage landing zone and depth, before and after volume loading, at $90(\mathbf{a} / \mathbf{b})$ and 135 degrees $(\mathbf{c} / \mathbf{d})$

feasible and IV fluid administration may trigger some complications such as pulmonary edema, particularly in patients with reduced LVEF, we opted to give a smaller volume of normal saline. This strategy proved to be well tolerated, and all examinations were performed without any adverse events. Moreover, the predicted device size based on the LZ dimensions taken post volume loading correlated well with the device size that was actually implanted in $71 \%$ of patients. Conversely, similarly to what has been previously reported [8], sizing based on the 2D maximum diameter of the LZ before volume loading correlated poorly with the device size finally selected (42\%). It is noteworthy that the timing and optimal volume of the saline infusion should be the object of further studies. An individualized dose of saline taking into account LVEF and adapted to body surface area might be a better choice. Also, volume loading might be administered before TEE probe insertion, however, it is important to take into account that the physiological effects of a fluid bolus typically dissipates within the hour [15].

During the evaluation phase of patient suitability for LAA closure, being able to accurately define the 


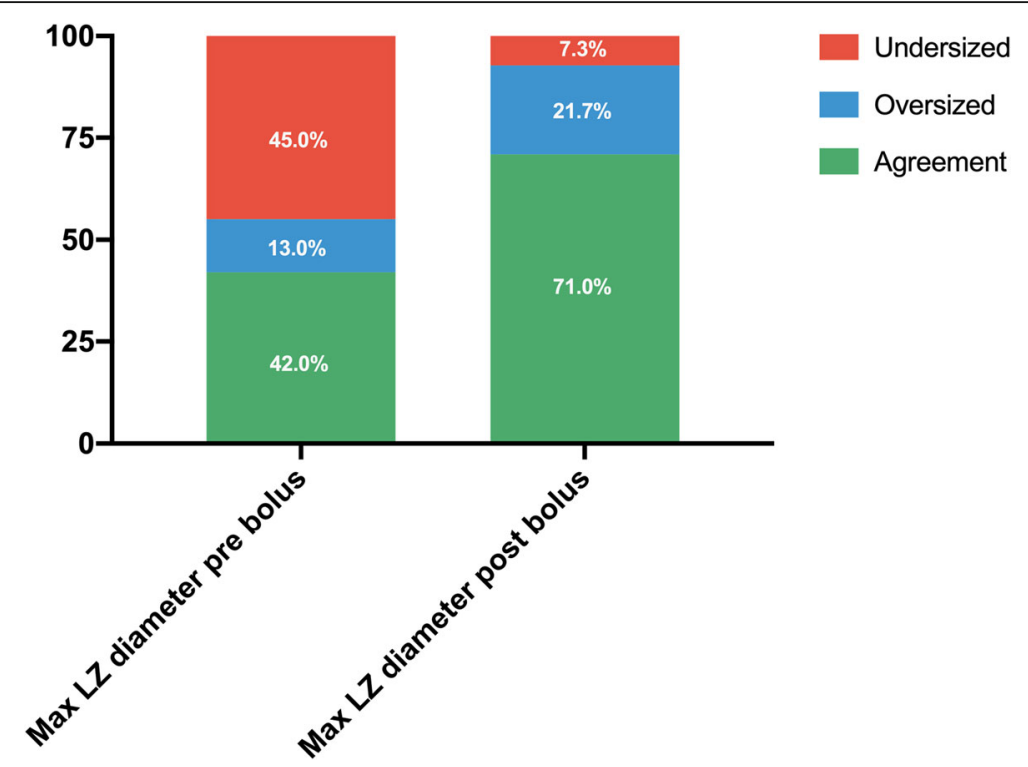

Fig. 3 Agreement between the device size that was actually implanted and the predicted size based on the largest landing zone diameter measured pre-procedurally, before and after fluid bolus. LZ: landing zone

anatomy and predict the device to be implanted is crucial as it allows for the Heart Team to make a more informed preprocedural evaluation. For instance, one of the most commonly used devices, the Watchman device, requires an implant depth equal to the orifice diameter, and thus cannot be implanted in a shallow LAA. As such, one benefit of administering a volume loading during preprocedural evaluation is to avoid contraindicating the procedure on the basis of on an incorrect depth. This is also applicable to other devices, where an incorrect measurement can erroneously contraindicate a procedure. It is of note that the use of $2 \mathrm{D}$ imaging to define the varied and complex morphology of the LAA may fail to depict its true dimensions, and other imaging techniques/modalities such as real time 3D-TEE and multidetector computed tomography-based LAA sizing may be more accurate methods, especially if undertaken in an euvolemic state $[8,16,17]$. Also, some authors have suggested performing the LAAC procedure with no procedural TEE guidance in order to avoid general anesthesia and facilitate patients' recovery [9-11]. In these cases, procedural LAAC guidance is based on fluoroscopy [9] or intracardiac echocardiography [10, 11 ], and device sizing is mainly based on pre-procedural TEE measurements. In such cases, the strategy of volume loading during pre-procedural TEE would be key in order to provide reliable measurements and avoid complications related to inaccurate device sizing.

\section{Limitations}

Our study has several limitations. This report consisted of an observational single-center study with a retrospective analysis and a relatively small number of patients, which limits the strengths of our results. Imaging the LAA may be challenging in some cases and it was not always possible to obtain identical images before and after volume loading. Also, observer variability was not investigated, and the lack of blinding regarding patients' fluid status may have introduced some degree of measurement bias. However, in order to reduce interobserver variability and maintain consistency, all studies were analyzed by a single measurer and the magnitude of increase in LAA size found in our cohort was consistent with previous studies [7, 8]. Additionally, due to logistical and technical reasons, we were unable to analyze $3 \mathrm{D}$ data, which is in theory a more accurate method to size the LAA and might have yielded larger dimensions. Some patients might have started with an adequate volume status, which might be one of the reasons for the smaller increase in LAA dimensions found in some cases. Lastly, regarding the safety of administering a $500 \mathrm{ml}$ IV fluid bolus, even though the procedure was well tolerated by all patients included in the cohort, we acknowledge that the size and design of the study does not lend itself to generalize our results since patients with heart failure and reduced LVEF were in the minority.

\section{Conclusions}

Similar to what has been previously reported for intraprocedural LAA closure, volume loading during baseline preprocedural TEE is safe and significantly increases the $\mathrm{LZ}$ and depth of the LAA. This strategy improves sizing and more accurately predicts the device size that will be implanted in a subsequent intervention, which may be 
particularly relevant in LAAC procedures performed without TEE guidance.

\section{Abbreviations}

AF: Atrial fibrillation; IQR: linterquartile range; LAAC: Left atrial appendage closure; LZ: Landing zone; TEE: Transesophageal echocardiography; IV: Intravenous

\section{Acknowledgements}

Dr. Freitas-Ferraz was supported by a research grant from the Quebec Heart \& Lung Institute Fondation. Drs. Junquera, Alperi, and Muntané-Carol are supported by a grant from the Fundacion Alfonso Martin Escudero (Madrid, Spain). Dr. Rodés-Cabau holds the Research Chair "Fondation Famille Jacques Larivière" for the Development of Structural Heart Disease Interventions.

\section{Authors' contributions}

ABFF: Drafting article, Data collection, Data analysis/interpretation, Critical revision of article, Approval of article. MB: Concept/design, Critical revision of article, Data collection, Approval of article. KOC: Critical revision of article, Data collection, Approval of article. JB: Critical revision of article, Data collection, Approval of article. JC: Critical revision of article, Data collection, Approval of article. JMP: Critical revision of article, Data collection, Approval of article. GOH: Critical revision of article, Data collection, Approval of article GMC: Critical revision of article, Data collection, Approval of article. AA: Critical revision of article, Data collection, Approval of article. LF: Critical revision of article, Data collection, Approval of article. LJ: Critical revision of article, Data collection, Approval of article. JRC: Concept/design, Data collection, Data analysis/interpretation, Critical revision of article, Approval of article.

\section{Funding}

This research did not receive any specific grant from funding agencies in the public, commercial, or not-for-profit sectors.

\section{Availability of data and materials}

The datasets used and/or analysed during the current study are available from the corresponding author on reasonable request.

\section{Ethics approval and consent to participate}

All patients provided informed consent for the procedures and Ethics committee approval was obtained for data collection and analysis.

\section{Consent for publication}

Not applicable.

\section{Competing interests}

Dr. Rodés-Cabau has received institutional research grants from Edwards Lifesciences, Medtronic, and Boston Scientific. The rest of authors do not report any relationships relevant to the contents of this paper to disclose.

Received: 20 September 2020 Accepted: 3 December 2020

Published online: 02 January 2021

\section{References}

1. Go AS, Hylek EM, Phillips KA, et al. Prevalence of diagnosed atrial fibrillation in adults: national implications for rhythm management and stroke prevention: the AnTicoagulation and Risk Factors in Atrial Fibrillation (ATRIA) Study. JAMA. 2001:285(18):2370-5. https://doi.org/10.1001/jama.285.18.2370.

2. Henninger N, Goddeau RP Jr, Karmarkar A, Helenius J, McManus DD. Atrial Fibrillation Is Associated With a Worse 90-Day Outcome Than Other Cardioembolic Stroke Subtypes. Stroke. 2016;47(6):1486-92. DOl:https://doi. org/10.1161/strokeaha.116.012865.

3. Alkhouli M, Noseworthy PA, Rihal CS, Holmes DR. Jr. Stroke Prevention in Nonvalvular Atrial Fibrillation: A Stakeholder Perspective. J Am Coll Cardiol. 2018;71(24):2790-801. DOl:https://doi.org/10.1016/j.jacc.2018.04.013.

4. January CT, Wann LS, Calkins H, et al. 2019 AHA/ACC/HRS Focused Update of the 2014 AHA/ACC/HRS Guideline for the Management of Patients With Atrial Fibrillation: A Report of the American College of Cardiology/American Heart Association Task Force on Clinical Practice Guidelines and the Heart Rhythm Society in Collaboration With the Society of Thoracic Surgeons.
Circulation. 2019;140(2):e125-51. DOl:https://doi.org/10.1161/cir 0000000000000665

5. Kirchhof P, Benussi S, Kotecha D, et al. 2016 ESC Guidelines for the management of atrial fibrillation developed in collaboration with EACTS. Eur Heart J. 2016;37(38):2893-962. DOl:https://doi.org/10.1093/eurheartj/ehw210.

6. Reddy W, Doshi SK, Kar S, et al. 5-Year Outcomes After Left Atrial Appendage Closure: From the PREVAIL and PROTECT AF Trials. J Am Coll Cardiol. 2017;70(24):2964-75. DOl:https://doi.org/10.1016/j.jacc.2017.10.021.

7. Spencer RJ, DeJong P, Fahmy P, et al. Changes in Left Atrial Appendage Dimensions Following Volume Loading During Percutaneous Left Atrial Appendage Closure. JACC Cardiovasc Interv. 2015;8(15):1935-41. https://doi. org/10.1016/j.jcin.2015.07.035.

8. Al-Kassou B, Tzikas A, Stock F, Neikes F, Völz A, Omran H. A comparison of two-dimensional and real-time 3D transoesophageal echocardiography and angiography for assessing the left atrial appendage anatomy for sizing a left atrial appendage occlusion system: impact of volume loading. Eurolntervention. 2017;12(17):2083-91. https://doi.org/10.4244/eij-d-1500543.

9. Koskinas KC, Shakir S, Fankhauser M, et al. Predictors of Early (1-Week) Outcomes Following Left Atrial Appendage Closure With Amplatzer Devices. JACC Cardiovasc Interv. 2016;9(13):1374-83. DOl:https://doi.org/10. 1016/j.jcin.2016.04.019.

10. Hemam ME, Kuroki K, Schurmann PA, et al. Left atrial appendage closure with the Watchman device using intracardiac vs transesophageal echocardiography: Procedural and cost considerations. Heart Rhythm. 2019; 16(3):334-42. DOl:https://doi.org/10.1016/i.hrthm.2018.12.013.

11. Velagapudi $P$, Turagam MK, Kolte $D$, et al. Intracardiac vs transesophageal echocardiography for percutaneous left atrial appendage occlusion: A metaanalysis. J Cardiovasc Electrophysiol. 2019;30(4):461-7. DOl:https://doi.org/10. 1111/jce.13820.

12. Piccini JP, Sievert H, Patel MR. Left atrial appendage occlusion: rationale, evidence, devices, and patient selection. Eur Heart J. 2017;38(12):869-76. DOl:https://doi.org/10.1093/eurheartj/ehw330.

13. Asmarats L, Rodés-Cabau J. Percutaneous Left Atrial Appendage Closure: Current Devices and Clinical Outcomes. Circ Cardiovasc Interv 2017;10(11). DOl:https://doi.org/10.1161/circinterventions.117.005359.

14. Wilkins B, Fukutomi M, De Backer O, Søndergaard L. Left Atrial Appendage Closure: Prevention and Management of Periprocedural and Postprocedural Complications. Card Electrophysiol Clin. 2020;12(1):67-75. DOl:https://doi. org/10.1016/j.ccep.2019.10.003

15. Hilton AK, Bellomo R. A critique of fluid bolus resuscitation in severe sepsis. Crit Care (London England). 2012;16(1):302. DOl:https://doi.org/10.1186/ cC11154.

16. Chow DH, Bieliauskas G, Sawaya FJ, et al. A comparative study of different imaging modalities for successful percutaneous left atrial appendage closure. Open heart. 2017;4(2):e000627. DOl:https://doi.org/10.1136/openhrt2017-000627.

17. Wang DD, Eng M, Kupsky D, et al. Application of 3-Dimensional Computed Tomographic Image Guidance to WATCHMAN Implantation and Impact on Early Operator Learning Curve: Single-Center Experience. JACC CardiovasC Interv. 2016;9(22):2329-40. DOl:https://doi.org/10.1016/j.jcin.2016.07.038.

\section{Publisher's Note}

Springer Nature remains neutral with regard to jurisdictional claims in published maps and institutional affiliations.

Ready to submit your research? Choose BMC and benefit from

- fast, convenient online submission

- thorough peer review by experienced researchers in your field

- rapid publication on acceptance

- support for research data, including large and complex data types

- gold Open Access which fosters wider collaboration and increased citations

- maximum visibility for your research: over $100 \mathrm{M}$ website views per year

At $\mathrm{BMC}$, research is always in progress.

Learn more biomedcentral.com/submissions 